\title{
Analysis of the Reason and Countermeasure of Higher Vocational College Students' Exam Cheating
}

\author{
Lijun Liu \\ Sichuan Information Technology College, Sichuan Guangyuan, 628017, China. \\ 153947614@qq.com
}

\begin{abstract}
Honesty is the traditional Chinese ethics of the most important basic norms. Currently, higher vocational colleges in the constant development and expansion of the meanwhile, Often ignored the credit education of students. Exam cheating is a long-standing problem which is hard to eliminate. Exam cheating is very common in higher vocational college. Combining the learning state of students in higher vocational colleges, this paper analyzes the causes of cheating in exams and puts forward the corresponding countermeasures.
\end{abstract}

Keywords: Exam-cheating; causes; countermeasures.

\section{Introduction}

The purpose of the examination is to test the students' learning achievement and learning progress. Also it can promote the further study in the future. From the test date of birth, cheating has been accompanied. Whenever there is an exam, there must be cheating. In recent years, higher vocational education in our country has been greatly developed, but there are also many problems. The cheating in the exam is one of the bad phenomenon commonly existing in higher vocational colleges, and its trend is spreading. The harm it brings has aroused wide attention in the society. Measures should be taken to prevent it from happening.

\section{Reasons for Cheating in Examinations}

\subsection{Adverse Social Factors.}

China is building a well-off society in an all-round way. Economic development has achieved remarkable achievements, but also associated with some negative effects. Some people in the society abuse the power to seek personal gain. Money is used to get good scores. What is worse, some people even find a gunman to take part in the examinations. These undesirable phenomena inevitably have an impact on students' psychology and behavior. Some students lack of awareness of cheating and sense of shame and they may think that cheating is a shortcut through the exam. When in the exam, once the opportunity occurs, they will cheat at once.

\subsection{The Influence of Employment Pressure.}

The employment pressure is one of the outstanding problems in the expansion of college enrollment. In 2006, higher vocational college graduates signing rate was only $39.08 \%$, the employment situation is grim. In order to stand out in the competition of employment, some students who do not usually try hard will cheat. Also, in order to become more excellent, some top students chose to cheat in the exam.

\subsection{The Lag of Social Credit System.}

The lag of social credit system has indulged the behavior of dishonesty in higher vocational students. The system is the important foundation and the main way to form the order. The imperfection of the system will have a negative effect on the principle of good faith. At present, the integrity in our country is basically a range of self-discipline constraints. The principle of good faith in law is limited to the specific contractual relationship, and some of the laws and provisions are contradictory. The law against the dishonesty behavior is not enough. In addition, our country has not paid enough attention to the construction of social credit system for a long time. In the higher vocational colleges, the general lack of supervision and punishment mechanism for the dishonesty students in vocational colleges is very common. This is mainly caused by the relative lag of the 
system construction in the process of system transformation, and this situation will inevitably bring a great negative impact on the quality of the higher vocational students' integrity.

\subsection{The Lack of Family Integrity Education Concept.}

According to some social studies, the family is the main group of individual socialization, it is the basic cell of the society, and it is also the main activity place of the children. It is the Enlightenment of the integrity education. Parents play an important role in the moral education of young people's integrity. However, due to various reasons, and now the family of the children's integrity education concept is not strong, and even some parents have many problems in the education of children. Firstly, only focus on the economic support. Secondly, they pay more attention on the intellectual education than the moral education. Thirdly, adverse effects of some parents' dishonesty behavior. In this sense, parents want their children to have what quality, they should have the quality at first.

\section{Countermeasures of Exam Cheating}

\subsection{Strengthen the Integrity Education in Higher Vocational Colleges.}

Vocational colleges should strengthen the integrity education courses and the integrity education should be put into the school ideological education system. According to dialectical materialism epistemology and human development theory, it can help students understand the good faith principle and the world outlook of Marx's philosophy, which provide the theory basis for the principle of good faith. In the course of Ideological and moral cultivation, it should pay attention to the infiltration of the concept of integrity education, and fully tap the ideological nature of the teaching materials. In this way, it can cultivate students' good faith quality in all aspects of teaching. In the teaching process, teachers should help students understand the honesty and trustworthiness is not only a moral category, but also a legal awareness.

Campus culture is a kind of culture form which is formed by the culture of a university for many years. It is the embodiment of school spirit and style. It plays a great role in shaping the personality of students, improving the overall quality of students and promoting the development of students. Campus cultural activities are the main activities of the campus. It takes the students as the main body and the campus spirit as the characteristic. Through the expansion of various forms of campus cultural activities, it can enhance the effect of integrity education.

Vocational colleges should actively explore the construction of students' credit evaluation system and improve the integrity education. Specifically, the establishment of credit evaluation system for higher vocational college students can be carried out from the following three steps. Firstly, establish the higher vocational college students' credit files. Integrity file is an objective description of the students in a realistic way. It is a kind of precious resource, which can make the student remind themselves to pay attention to the behavior at the moment. Secondly, establish a scientific and effective credit evaluation system. Credit evaluation can make the abstract concept of integrity specific. At the same time, it can consolidate the credibility belief and improve the ability to tell the difference between right and wrong. It can effectively control and guide their integrity behavior. Thirdly, improve the incentive and supervision mechanism of integrity.

The construction of integrity education team in higher vocational colleges is very important. Teachers play a leading role in this process, which is related to the realization of higher vocational students' integrity education goals. Therefore, efforts to strengthen the integrity education team and ensure the integrity implementation is the key to improve the integrity of higher vocational education.

\subsection{Create a Social Credit Atmosphere.}

Credibility is based on public opinion, all forms of education, tradition and habits. In order to make honest become a habit, the concept in deep in heart is the most important premise. The cultivation of higher vocational students' sense of integrity requires the support of the whole social environment. Propagating the correct guidance of public opinion and integrity concept is imperative.

Under the condition of market economy, with the continuous accumulation of social credit, its social effect and economic effect will expand rapidly. Social credit system has become an important mechanism in the economic system. Good social credit system can greatly reduce the market 
operation of the transaction costs and improve the efficiency of the market operation. Only through the establishment of a sound and stable management system of integrity, can integrity rise to a wide range of topics of concern to the whole society.

The legal safeguard system of scientific standard is the premise of integrity, it can provide the basic guarantee for the establishment of integrity society. Because the construction of our country's integrity laws and regulations are relatively weak and there is no special integrity management law. Therefore, the supervision of integrity is difficult to be included in the track and it is difficult to fully carry out. Under the condition of market economy, once the credit is protected by law, people will realize the interests in the legal channels. Integrity is the integrity of society, only when the public correctly identifies the value of integrity and the law provides a guarantee for the value of integrity, integrity education in higher vocational colleges can play a real role.

\subsection{Optimize the Family Integrity Environment.}

The family is the first environment for people. It plays a subtle role for human behavior. Parents are the first teachers of the people, their behavior is the object of the original imitation. Honest parents and a harmonious family, are the beginning and protection of integrity education. Therefore, parents' attention to their children's integrity education is very important. Parents' education, should not be confined to the moral language, but more of their moral behavior to children's subtle influence. Parents should pay attention to their own words and deeds when they are in integrity education for their children. Because children have a strong ability to imitate, in particular, they are easy to imitate the behavior of parents. When dishonest signs appear in children, parents should promptly find and properly handle. What is more, they should guide the children to realize the wrong place and tell them not do it again.

\section{Summary}

Honesty is the traditional Chinese ethics of the most important basic norms. Currently, higher vocational colleges in the constant development and expansion of the meanwhile, often ignored the credit education of students. In the view of honesty education connotation and the absence of credibility higher vocational students' present situation, the paper discusses the causes of dishonesty in vocational colleges. In order to improve the integrity quality of vocational students, the credibility countermeasures are discussed, hoping to find solutions to problems, so as to build the harmonious society in the future.

\section{References}

[1] Principles of the Brown University Community: The Academic Code and Nonacademic Conduct, 2007, 45-47.

[2] Gehring, D., Nuss, E. M., \& Pavela, G (1986). Issues and Perspectives on Academic Integrity. Washington, D. C: National Association of Student Personnel

[3] Administrators, 21-23.

[4] Astin, A. W. (1984). Student Values: Knowing More about Where We are today. AAHE Bulletin, 38(9), 10-13.

[5] Li Wenbin., Analysis of the Reason and Countermeasure of Higher Vocational College Students' Exam Cheating. Value Engineering, 2014(9): 315-316

[6] Jiang Hao, Ai Honghui, Analysis and Countermeasure Research on the Motivation of Students' Examination Cheating in Higher Vocational Colleges. Vocational Education Research, 2007(5): 144-145. 